\title{
The impact of traumatic brain injuries: A global perspective
}

\author{
Adnan A. Hyder ${ }^{\mathrm{a}, *}$, Colleen A. Wunderlich ${ }^{\mathrm{b}}$, Prasanthi Puvanachandra ${ }^{\mathrm{a}}$, G. Gururaj ${ }^{\mathrm{c}}$ and \\ Olive C. Kobusingye ${ }^{\mathrm{d}}$ \\ ${ }^{a}$ Department of International Health and Center for Injury Research \& Policy, Johns Hopkins Bloomberg School of \\ Public Health, USA \\ ${ }^{\mathrm{b}}$ Medical College of Virginia/Virginia Commonwealth University Health System and Children's Hospital, USA \\ ${ }^{\mathrm{c}}$ National Institute of Mental Health and Neurosciences, India \\ ${ }^{\mathrm{d}}$ World Health Organization Regional Office for Africa
}

\begin{abstract}
Traumatic brain injury (TBI), according to the World Health Organization, will surpass many diseases as the major cause of death and disability by the year 2020. With an estimated 10 million people affected annually by TBI, the burden of mortality and morbidity that this condition imposes on society, makes TBI a pressing public health and medical problem. The burden of TBI is manifest throughout the world, and is especially prominent in Low and Middle Income Countries which face a higher preponderance of risk factors for causes of TBI and have inadequately prepared health systems to address the associated health outcomes. Latin America and Sub Saharan Africa demonstrate a higher TBI-related incidence rate varying from 150-170 per 100,000 respectively due to RTIs compared to a global rate of 106 per 100,000. As highlighted in this global review of TBI, there is a large gap in data on incidence, risk factors, sequelae, financial costs, and social impact of TBI. This should be addressed through planning of comprehensive TBI prevention programs in LMICs through well-established surveillance systems. Greater resources for research and prioritized interventions are critical to promote evidence-based policy for TBI.
\end{abstract}

Keywords: Traumatic brain injury, injury epidemiology, injuries, developing countries, brain trauma

\section{Introduction}

Traumatic brain injury (TBI) is a critical public health problem worldwide. However, since the problems experienced by those suffering TBI, such as impairments in memory or cognition, are often not visible, it has been referred to as the "silent epidemic" [45]. Of all types of injury, those to the brain are among the most likely to result in death or disability [1]. TBI, according to the World Health Organization (WHO), will surpass many diseases as the major cause of death and disability by the year 2020. It has been estimated that TBI affects over 10 million people annually leading to

*Address for correspondence: Dr. Adnan A. Hyder, M.D., M.P.H., Ph.D, Johns Hopkins, Bloomberg School of Public Health, 615 North Wolfe Street, Suite E-8132, Baltimore, MD 21205, USA. Tel.: +1 410955 1253; Fax: +1 410614 1419; E-mail: ahyder@jhsph.edu. either mortality or hospitalization. Available data indicate that nearly $60 \%$ of TBIs are due to road traffic injuries (RTIs) in all parts of the world; about 20-30\% are due to falls; $10 \%$ due to violence, and another $10 \%$ due to combination of work place and sports related injuries [24].

Efforts to quantify the magnitude of TBI are hampered by many factors. Firstly, minor TBI, the majority of all brain injuries, is difficult to capture, as only few receive medical treatment. Secondly, TBI may be caused by war and civil unrest, occurs in the context of multi-trauma, and is usually under-reported or rolled up into other causes of death and injury statistics. Thirdly, TBI may be under-represented given its silent nature and the absence of injury surveillance or reporting systems in many part of the world. Fourthly, although WHO has defined parameters for adult central nervous system disorders in 1993 [79], there is at present, no 
internationally accepted method of defining severity or longevity of childhood disability from TBI, and individual nations each have their own health patterns of use and provision [78].

Given these challenges, this paper attempts to summarize the epidemiology of TBI in a worldwide context by describing the burden of TBI in high, and lowmiddle income countries; provides examples and case studies from developing regions; and then summarizes the implications for research and control measures. To this end, we have purposefully chosen to focus on selected data sources (from 1990 onwards) that offer a global perspective of TBI and those that highlight the most significant issues, rather than pursue a systemic review of all worldwide sources. The term head injury potentially covers not only those injuries resulting in a change in brain function (an altered level of conscious, confusion, coma, convulsions, or other signs of neurological deficit) but also injuries to the bones and soft tissues of the face and head but not involving the brain. In this paper, the term traumatic brain injury will be used to incorporate all types of head injury including those studies where head injury is used without further clarification or where TBI are not differentiated from other injuries to the head.

\section{Global burden of TBI}

In 2002, injuries were responsible for killing 4.5 million adults, equating to 1 in 10 of total adult deaths [81]. Injuries are among the top 15 causes of death in all age groups less than 60 years old with road traffic injuries, self-inflicted injuries and violence consistently among the leading 15 causes of death. Taking disabilities into account places the burden of disease due to injury higher as shown in Fig. 1 from the WHO Global Burden of Disease estimates. The Disability Adjusted Life Years (DALYs) losses are higher for low-income countries due to injuries for all causes with the exception of selfinfliction and violence [80]. Overall the DALY losses for RTI and other unintentional injuries are highest; TBI is an important and often critical sequelae of these injuries.

A systematic review of Pubmed/Medline did not reveal any recent reviews on the global burden of TBI. This, together with the inconsistencies in defining TBI and poor reporting systems in many LMICs makes for scarcity of data. It is also noted that many injury analyses do not portray outcomes and hence, it cannot be determined what proportion of these injuries result in head injury. As a result, the most recent database from which we are able to construct a global picture of TBI is from the 1996 Global Burden of Disease (GBD) study [60] which categorizes injuries by cause and outcome. The reported outcomes of "fractured skull" (long and short term) and "intracranial injury" (long and short term) for five causes of injury (RTIs, falls, other unintentional injuries, violence and war) have been used here to estimate a global burden of TBI. For the purposes of this paper, these outcomes have been defined as "TBIrelated outcomes".

Table 1 highlights the regional differences in incidence rates across the 8 regions used in the GBD study. The highest rates of TBI due to RTIs are in the Latin American and Caribbean region with rates in Sub Saharan Africa not far behind. These same regions also demonstrate the highest rates for TBI-related outcomes due to violence. With an incidence rate of 42.6 per 100,000 , India has the greatest rate of TBI-related injuries due to falls. Overall, TBI-related outcomes from RTI might involve between 700,000 and 5.6 million people annually ranging from severe long term to mild head injury respectively [65].

The global distribution of TBI related outcomes (fractured skull, short and long term intracranial injury) for all ages is shown in Fig. 2. Globally, RTI is seen to cause over $60 \%$ of such outcomes thus highlighting the significant public health nature of this problem. Violence is also seen to be an important cause of TBI reflecting the high number of cases in Sub Saharan Africa and Latin American and Caribbean regions. The regional distributions of TBI related outcomes (fractured skull, short and long term intracranial injury) by cause of injury are shown in Fig. 3. The distribution of RTIs are fairly evenly spread across most regions further highlighting that this issue is not solely associated with high income countries. India accounts for $50 \%$ of TBI-related outcomes from falls and a fourth of cases related to unintentional injuries. The effect of civil unrest and ethnic tensions in the Middle Eastern Crescent is reflected in the regional distribution of war-related TBI; while civil unrest and societal violence might have caused a high proportion of TBI in Sub Saharan Africa.

Whilst current and past estimations demonstrate the burden of TBI, what is worrying is the future trend of TBI. RTIs are currently the leading cause of TBI and WHO estimate that they will be the $3^{\text {rd }}$ leading cause of premature death amongst all age categories by the year 2020 [59]. Thus it is to be expected that subsequent brain injury is set to become a significant burden, particularly within the developing world. Similarly, 
Table 1

Incidence rates (per 100,000) of traumatic brain injury related outcomes (fractured skull, short and long term intracranial injury) by cause (1996)

\begin{tabular}{|c|c|c|c|c|c|c|c|c|c|c|}
\hline \multirow[b]{2}{*}{ Cause } & \multirow[b]{2}{*}{ Injury Sustained } & \multicolumn{9}{|c|}{ Incidence Rates (per 100,000) } \\
\hline & & EME & FSE & India & China & OAI & SSA & LAC & MEC & World \\
\hline \multirow[t]{3}{*}{ Road Traffic Accident } & Fractured Skull & 0.8 & 1 & 0.9 & 0.5 & 0.8 & 1.2 & 1.3 & 0.6 & 0.8 \\
\hline & Intracranial Injury Short Term & 97 & 123 & 119 & 63 & 106 & 156 & 163 & 78 & 106 \\
\hline & Intracranial Injury Long Term & 4.6 & 6.8 & 42.6 & 7.7 & 13.7 & 6 & 6.2 & 7.4 & 13.3 \\
\hline \multirow[t]{2}{*}{ Falls } & Fractured Skull & 0.6 & 1.4 & 5.9 & 2.1 & 4.4 & 2.8 & 2 & 2.7 & 2.9 \\
\hline & Intracranial Injury Long Term & 4.6 & 6.8 & 42.6 & 7.7 & 13.7 & 6 & 6.2 & 7.4 & 13.3 \\
\hline Other Unintentional Injuries & Intracranial Injury Long Term & 2.5 & 5.2 & 9.8 & 6.8 & 7.7 & 13.4 & 7.1 & 5.5 & 7.2 \\
\hline \multirow[t]{3}{*}{ Violence } & Fractured Skull & 0.2 & 0.3 & 0.3 & 0.3 & 0.4 & 1.6 & 0.6 & 0.4 & 0.5 \\
\hline & Intracranial Injury Short Term & 31.9 & 54.7 & 28 & 25.4 & 34.6 & 144 & 66.5 & 7.6 & 43 \\
\hline & Intracranial Injury Long Term & 1.6 & 2.7 & 1.4 & 1.3 & 1.7 & 7.2 & 3.3 & 0.4 & 2.2 \\
\hline War & Intracranial Injury Long Term & 0 & 3.3 & 0 & 0 & 0.9 & 20.7 & 1.5 & 13.3 & 3.8 \\
\hline
\end{tabular}

$\mathrm{EME}=$ Established Market Economies; FSE = Former Socialist Economies of Europe; IND = India; CHN = China; 0AI = Other Asia and Islands; SSA = Sub-Saharan Africa; LAC = Latin America and Caribbean; MEC = Middle Eastern Crescent.

Source: Murray CL and Lopez A. Global Burden of Disease, 1996 [59].

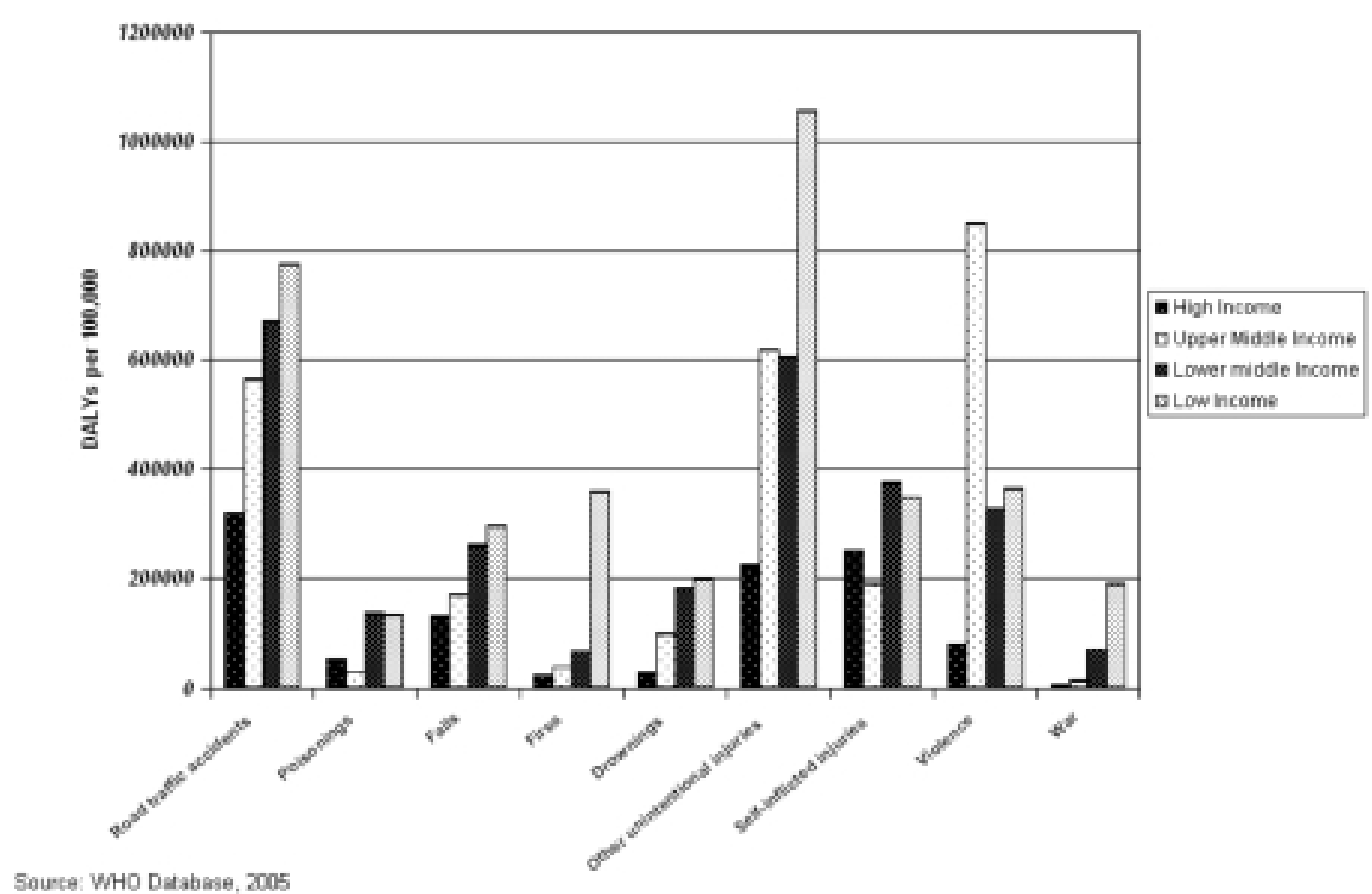

Fig. 1. Projected DALYs for injuries by cause and income level, 2005.

the increasing trends for political and civil violence in Sub-Saharan Africa, the Middle East and other regions portends negatively for TBI.

Data from individual countries also gives a snapshot global perspective of the burden of TBI and demonstrates the noticeable variations amongst developed and developing nations. A study from Germany reported an incidence of TBI of 350 per 100,000 and a mor- tality rate of 11.5 per 100,000 with the leading cause being RTIs [19]. It noted that approximately $68 \%$ of those who dies as a result of head injuries, did so before arriving at hospital. In contrast, a study from neurological centres in Pakistan [34] revealed an incidence rate for TBI of 50 per 100,000 with RTIs and falls as the commonest causes. Of particular interest, $50 \%$ of TBI caused by falls were a result of falling from 


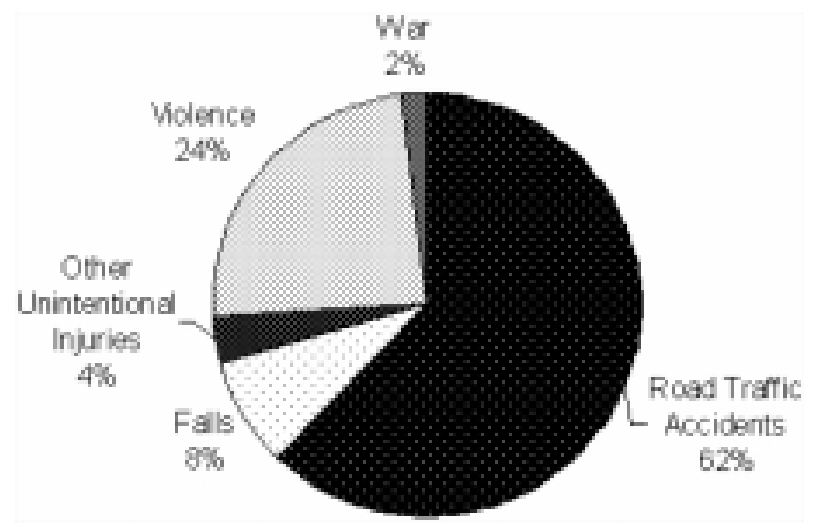

Fig. 2. Global distribution of TBI related outcomes (fractured skull, short and long term intracranial injury) by cause (1996).

rooftops; sleeping and kite flying with inadequate barriers on rooftops are unfortunately all too common in Pakistan [70].

The difference between TBI in cities versus rural areas is highlighted in a paper from China [84] where the incidence rates were reported as 6.3 and 9.7 per 100,000 respectively. This difference parallels a study conducted in the US (state of Colorado) where the TBI incidence rates for urban areas was 97.8 and 172.1 per 100,000 in the rural setting [20]. The implications of rural TBI are important to consider in the public health milieu given that access to tertiary neurosurgical facilities and rehabilitative services may be limited, and many cases of long term disability as a consequence of head injury tend to go unreported in the rural environment especially in the developing world [20].

A tri-modal age-specific TBI incidence is quite often seen in population based studies with peaks in early childhood, late adolescence/early adulthood and in the elderly [10]. While falls dominate among children and the elderly as causes, RTIs and violence contribute for majority of TBIs in young and middle aged adults. Although inconsistency of age categorization and confounding factors such as gender and income level might affect specific studies, overall these trends are common across studies. Findings from the United States reveal that for emergency department visits, hospitalizations, and deaths combined, infants aged 0 to 4 years and adolescents aged 15 to 19 years are more likely to sustain a TBI than other age groups [45]. Similarly a German study found that whilst mild head injury was more frequent in the under 2 year old category, intracranial injuries were more common in the older age groups [19].

WHO estimates that over $98 \%$ of childhood injuries occur in the poorest countries in the world with injury rates being 5 times higher than in industrialized na- tions. However there is a paucity of data regarding the incidence of TBI amongst children in the developing world [6]. The International Multicenter Study of Head Injury in Children [57] compiled data on all children ages 0 to 15 years seen in the emergency room and hospitalized across five countries - Argentina, Brazil, France, Hong Kong, and Spain. Minor injury accounted for $56 \%$ of these children, moderate $39 \%$, and severe $5 \%$, with a case fatality rate of $1.6 \%$. Of the victims $61 \%$ were boys and the majority of children $(55 \%)$ were aged 0 to 4 years. A study based in Nepal demonstrated that $96 \%$ of children admitted to hospital with an injury had sustained a TBI with falls being the commonest cause of injury $(61 \%)$. Of noticeable public health importance, the authors found that it took children from rural areas of Nepal, on average, 30 hours longer to obtain neurosurgical care than those injured in the capital of Khatmandu [55]. Although in part, this may be due to ongoing political unrest and geographical constraints within the country, this finding highlights important issues concerning access to care in the rural setting.

Gender differences in incidence of TBI have also been noted. Males consistently show a higher incidence in numerous studies with ratios ranging from 1.5:1 in the US [45] to 2.5:1 in rural China [84]. Whilst it is clear that the burden of TBI is significant on a global scale, there is concern that the situation across the world differs by regions significantly and TBI outcomes in low and middle income countries are far worse than in high-income settings. High rates of road traffic injuries, falls and violence; larger numbers of young people; and enhanced epidemiologic and demographic transitions create a high risk environment for TBI. As a result the following sections present TBI data disaggregated by regions with a special focus on low and middle income countries. 
a) RTA

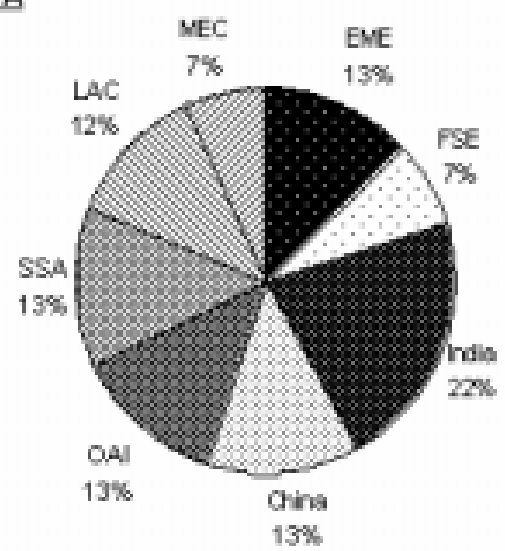

c) 0 ther Unintentional Injuries

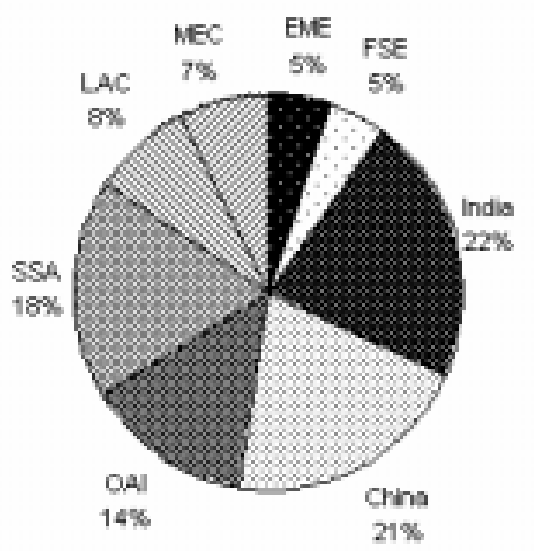

b)Falls

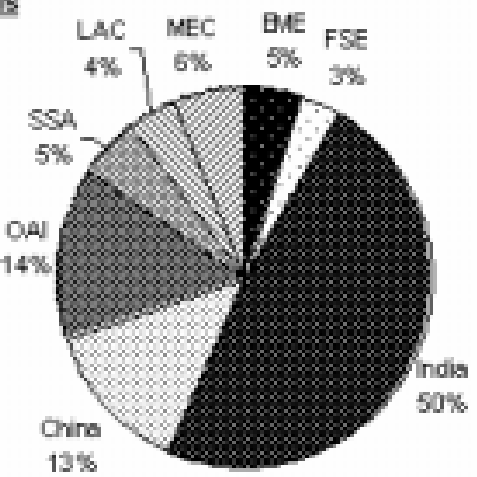

d) $\underline{\text { Violence }}$
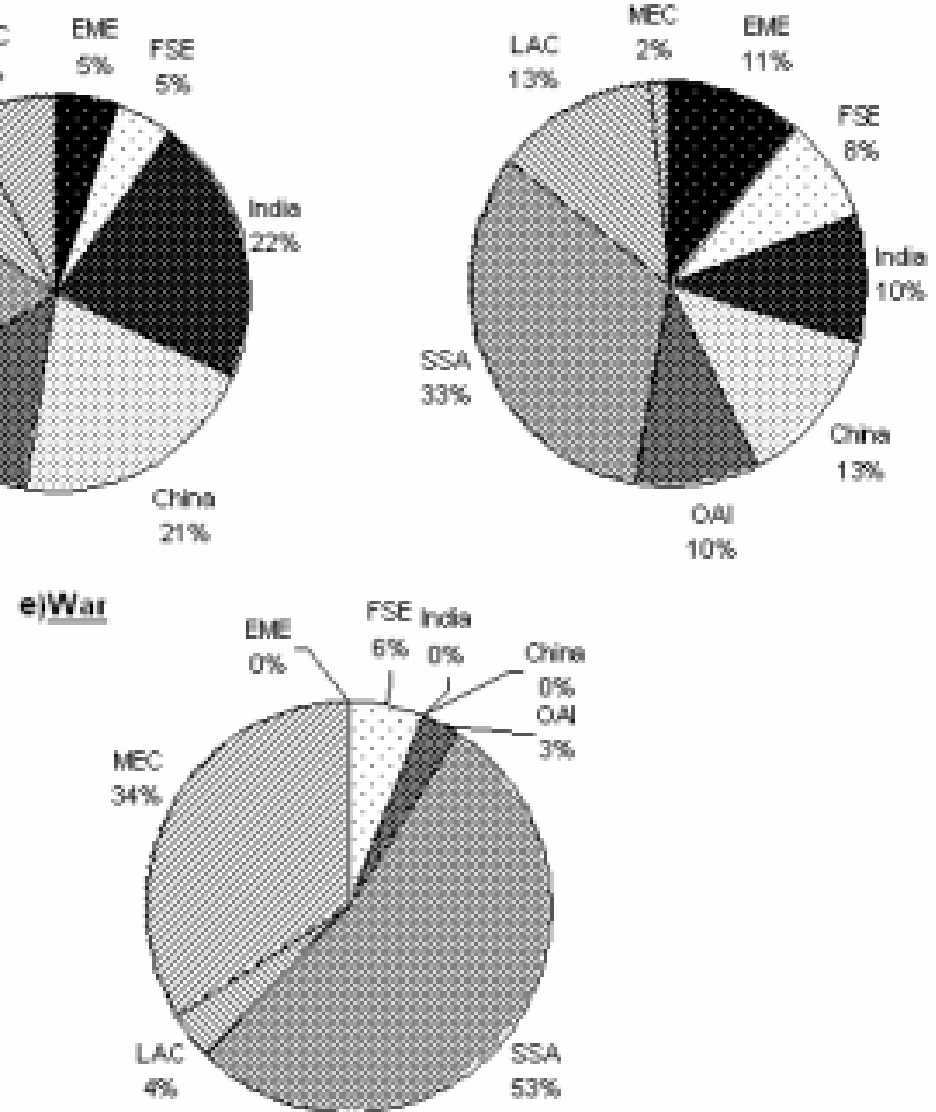

EME - Establithed Market Economies; FSE - Former Socialist Economies of Europe, IND - India; CHN = China; 0AI = Other Asia and Islands; SSA = Sub-Saharan Africa; LAC Latin Amenca and Canbbean; MEC = Middle Eastern Creacent. RTA = Road Traffic Accidents.

Source. Global Burden of Disease Study [33]

Fig. 3. Distribution of traumatic brain injury related outcomes (fractured skull, short and long term intracranial injury) by cause and region (1996) 


\section{Burden of TBI in high income countries}

Every 21 seconds, one person in the United Stated sustains a TBI [7]. An estimated 1.4 million TBIrelated deaths, hospitalizations, and ED visits occur in the United States each year [43]. Of these, 50,000 die, 235,000 are hospitalized, and 1.1 million are treated and released from an emergency department. An estimated 80.000 to 90,000 people with TBI experience permanent disability from their injury [77]. Adults aged 75 years and older have the highest rates of TBIrelated hospitalizations and death, with falls being the leading cause of TBI in this age group. Males are 1.5 times as likely to sustain a TBI than females; an average 835,000 TBIs are incurred by U.S. males compared with 561,000 among females [43]. U.S. males from $0-4$ years of age had the highest rate for TBIrelated deaths, hospitalizations, and ED visits combined $(1,355.3$ per 100,000), followed next by females aged $0-4$ years $(874.8$ per 100,000$)$. Rates next peaked for both males and females aged 15 to 19 years and 75 years and older showing a trimodal distribution. RTI causes the greatest number of TBI-related hospitalizations and accounts for $20 \%$ of all TBIs. African Americans and American Indians/Alaskan Natives have the highest death rate from TBI especially related to violence [43]; approximately four times the rate in white males [42].

Brain injury is the most frequent cause of disability and death among children and adolescents in the United States [47] more than one million children sustain a brain injury [17] and approximately one third of all pediatric injury cases are related to brain injury ) [2]. Falls are also the leading cause of TBI in children ages $0-4$ years, and RTIs are the second major cause; among children aged 4-14 however, RTI is the number one cause of TBI [7]. For children aged 0-9 years, both death and hospitalization rates were significantly higher for blacks than whites for RTI-related TBIs [44].

There were 16,811 hospitalizations as a result of TBI in Canada in 2003-2004, equating to 46 admissions every day [11]. There were 1,369 head-injury related deaths, representing $8 \%$ of the TBI admissions, twice the rate of death in all other causes of traumatic injury hospitalizations. Children aged 0-19 years accounted for $30 \%$ admissions, followed by the elderly (60 years and older). In Canadian children aged 0-19 years, falls accounted for $40 \%$ of all TBIs, closely followed by RTIs (39\%) during 2002-2003. RTIs were number one in groups aged 20-39 years and 40-59 years; with falls and violence being the other leading causes of TBI admission. $76 \%$ of all injuries in the elderly $(>60$ years) were caused by falls.

Trends in Canada show that there has been a $35 \%$ decrease in TBI admissions during the period 19941995 ( $n=25,665)$ and 2003-2004 $(n=16,811)$. The largest decrease $(53 \%)$ occurred in the $0-19$ years age group. Individuals 60 years and older account for the largest numbers of deaths secondary to TBI; there was a significant increase of $35 \%$ from 601 deaths in 19941995 to 809 in 2003-2004. While the overall number of TBI has decreased over the last decade, the number of severe TBI (Injury Severity Score $>12$ ) has increased recently in Canada by $46 \%$ from 3,880 in 2000-2001 to 5,660 in 2003-2004. The decreasing tends of TBI numbers in both US and Canada over the past two decades appear to be due to a mix of widespread implementation of prevention measures, safety legislation, and public education initiatives; improvements and wider availability of emergency medical systems and regional trauma centers; and improvements in neuro-critical care and implementation of evidence-based treatment guidelines for severe TBI [39].

In the European Union, TBI accounts for one million hospital admissions per year (www.nabis.org). A systemic review by Tagliaferri et al. [75] describes an aggregated (hospitalized and fatal) TBI incidence rate of 235 per 100,000 , average mortality rate of 15 per 100,000 , and case fatality rate of $11 \%$. The TBI severity ratio of mild to moderate to severe TBI for hospitalized patients was reported at 22:1.5:1. A retrospective epidemiological study of an emergency department database from the U.K. reports an overall incidence rate of 453 per 100,000 for all TBIs; of these 40 per $100,000(10.9 \%)$ were moderate to severe [83]. Males, urban residents, and children had significantly greater risk of presenting with moderate to severe head injury. Prospective data from pediatric intensive care units in the U.K. and Ireland between 2001-2003 showed that 5.6 per 100,000 children aged 0 to 14 years were admitted for TBI [64]. The commonest mechanism of injury was RTI; time of injury peaked in the late afternoon and early evening, independent of the day of week. Highest mortality occurred in RTI-related TBI, while requiring intensive care was found to be more common in children from poorer backgrounds [65]. In the UK, lowering speed limits has resulted in a $70 \%$ decrease in child pedestrian crashes and a near halving of crashes involving children on bicycles [79].

A childhood injury surveillance system in France reported TBI to account for $10 \%$ of all injuries in children less than 16 years [73]. A population-based study 
Table 2

Incidence Rates (per 100,000) of Traumatic Brain Injury Related Outcomes (Fractured Skull, Short \& Long Term Intracranial Injury) by Cause in the Latin American and Caribbean (LAC) region (1996)

\begin{tabular}{llccc}
\hline Cause & Injury Sustained & \multicolumn{2}{c}{ Incidence Rates per 100,000 } \\
\cline { 2 - 4 } & & Male & Female & Total \\
\hline Road Traffic Accidents & Fractured Skull & 1.6 & 0.8 & 1.3 \\
& Intracranial Injury Short Term & 231 & 95 & 163 \\
& Intracranial Injury Long Term & 8.6 & 3.8 & 6.2 \\
Falls & Fractured Skull & 2.7 & 1.4 & 2 \\
& Intracranial Injury Long Term & 8.6 & 3.8 & 6.2 \\
Other Unintentional Injuries & Intracranial Injury Long Term & 9.8 & 4.4 & 7.1 \\
Violence & Fractured Skull & 1 & 0.2 & 0.6 \\
& Intracranial Injury Short Term & 113.7 & 19.6 & 66.5 \\
War & Intracranial Injury Long Term & 5.7 & 1 & 3.3 \\
& Intracranial Injury Long Term & 1.8 & 1.3 & 1.5 \\
\hline
\end{tabular}

Source: Global Burden of Disease Study [59].

in France during 1996-2001 describes an annual incidence of severe TBI of 13.7 per 100,000 and mortality of 5.3 per 100,000 [37]; fatality rates increased from $20 \%$ in children to $71 \%$ in those over 75 years of age. In Germany, 279,029 persons in a population of 82 million were admitted to hospital for TBI in 1996 , and TBI caused the deaths of 9415 persons for a mortality of 11.5 per 100,000 [19]. A retrospective study of children aged 0 to 17 years in a Swedish health care region showed a mean incidence rate of 12 per 100,000 for TBI, with RTI causing $60 \%$ of TBI, followed by falls (22\%); although the incidence rate of TBI is low in Sweden, TBI causes permanent functional impairment in 6 per 100,000 cases every year [18].

Comparisons between regions of Europe showed differences in the distribution of ages, causes of TBI, outcomes, and several clinical characteristics in TBI patients in two concurrent randomized clinical drug studies of patients with TBI [33]. A database with validated software tools has been initiated across 16 European centers as part of an international network to provide more standardized and higher resolution data collection mechanisms [63]. This effort may allow research groups, organizations, and the industry to conduct multicentre trials of new health care technology in patients with traumatic brain injury.

A retrospective medical record review in South Australia, showed the incidence of TBI at 322 per 100,000 [32]. Causes, nature and severity of injury were found to be comparable, with young males living in the country showing the highest incidence, especially from RTI. Over 4,000 new case of TBI occur each year in South Australia and of these, over 1,000 will experience residual impairment. In New South Wales, Australia an annual incidence of 100 per 100,000 was calculated in a retrospective review con- ducted in 1988 [76]; $62 \%$ of TBIs were mild, $20.3 \%$ moderate, and $13.6 \%$ severe, while $3.9 \%$ died after hospital admission. Severe TBI had an annual incidence of 12 per 100,000, and road traffic injuries accounted for a higher proportion of severe TBI compared with other injury groups.

\section{Burden of TBI in low and middle income countries}

\subsection{Latin America and Caribbean (LAC)}

LAC consists of a large proportion of low to middle income countries with approximately $36 \%$ of the region's population living below the poverty line [48]. Studies stemming from Latin America regarding the burden of TBI are limited. Incidence rates for TBIrelated outcomes from the 1996 Global Burden of Disease Report [59] show the highest rates of intracranial injury following an RTI and violence (Table 1). The disaggregation of data for this region by gender is highlighted in Table 2 showing that males demonstrate a significantly higher rate than females for all cases. RTIs and their sequelae are becoming a significant health problem in Latin America; their causes are the focus of recent research in the region [31]. This region has the second highest rates for short term intracranial injury as a consequence of violence; and violence is the principal cause of death in Brazil, Columbia, Venezuela, El Salvador and Mexico [9].

Data from individual countries provides additional information on the extent of the burden of TBI in parts of Latin America. The incidence rate for TBI in Sao Paulo, Brazil was found to be 360 per 100,000 [16] which is much higher than the overall incidence rate 
of 200 per 100,000 for developed countries [10]. A study from Salvador City, Brazil which described the characteristics of victims of TBI, revealed that $83 \%$ were male with the most frequent age group being 21 to 30 years. The commonest cause was RTIs (41\%) however violence with or without weapons, was the second highest cause (25\%), closely followed by falls (24\%) [52]. Approximately 1,745 Mexicans are hospitalized as a result of TBI every year; males $(68 \%)$ and those aged 25-44 years are more likely to be affected [8]. Trends in causes of TBI follow a similar pattern with RTIs and falls as the leading two causes (43\% and $13 \%$ respectively) [8].

The causes of TBI amongst children in Latin America are highlighted in a study of 2,492 children where $33.5 \%$ were $0-2$ years, $43.8 \%$ between $3-9$ years and $22.7 \%$ from 10-15 years [58]. Falls were found to be the main cause of injury in children less than 3 years, and RTIs prevailed as the leading cause of TBI amongst older aged children. An incidence rate of 566 pediatric TBI cases per 100,000 and a corresponding mortality rate of 4.65 per 1,000 TBI cases was reported; this incidence rate is 2.97 times higher than the international average [58].

\subsection{Asia and Middle East}

A case study from Yemen revealed a prevalence of TBI of 219 cases per 100,000 (160 in adults and 480 in children per 100,000 population). The dominant cause of TBI was found to be "domestic" (which included a vast array of causes including falls and violence) and RTIs were the second leading cause [68]. A neurotrauma study of patients admitted to a referral hospital in Israel documented a crude incidence rate of TBI of 25.2 per 100,000 person-years. Almost twice this rate was found at the two extremes of age, with falls resulting in $51 \%$, RTIs in $36 \%$ of TBIs [49].

The burden of all injuries in Asia is high with RTIs and self inflicted injuries both within the top ten causes of mortality in the region $[26,35]$ RTIs are on the verge of an epidemic in the region with $44 \%$ of the world's road deaths occurring in Asia. The annual incidence of TBIs in India is estimated to be 160 per 100,000 with a mortality rate of 20 per 100,000 [25]. These figures are based on hospital TBI registration and translate to nearly 1.6 million people likely to sustain TBI with 200,000 estimated deaths. In a recent epidemiological study of TBIs, $59 \%$ were due to RTIs, $25 \%$ due to falls, and $10 \%$ due to assaults [72]. Amongst various studies from India $[14,30,66,69]$ there was a higher proportion of TBI caused by two-wheeled vehicles. In Kashmir, India more than $50 \%$ of RTI occurred in the 46 yrs age group and higher rates were seen among male children with the average age of hospitalization being 16-24 yrs [74]. A substantial number of TBI occur due to alcohol influence in Asia [15,29]; for example, a recent review observed that $10-30 \%$ of night time road crashes, which involve severe injuries such as TBI, are linked to alcohol [22].

In China, a recent study compared the incidence of TBI in urban and rural areas with incidence rates of 55 and 64 per 100,000 respectively [84]. The respective mortality rates in these settings were 6.3 and 9.7 per 100,000 . In Taiwan, RTI $(69 \%)$ was the major cause followed by falls and assaults [84]; mild TBI was also more likely to occur in unhelmeted riders of motorbikes, especially in children [46]. Pediatric minor head injuries are common in urban and rural areas in Malaysia; however, urban-based TBIs are due to RTI, whilst rural-based TBIs are due to other causes [12]. A hospital based paper studying a Vietnamese population in Hong Kong gives a unique description of head injuries sustained in a refugee camp setting [21]. There was an average incidence rate for TBI of 924 per 100,000 with a disproportionate number of children aged $<12$ years $(50 \%)$, and the most common cause being a fall from a bed. The authors noted that a three-tiered wooden bunk bed made available to families in the camp was not safe for children and they recommended that safety nets or railings should be put in place [21].

In a four year prospective study (1995-1999) of 260,000 patients admitted to various neurosurgical centers in Pakistan it was observed that the male to female ratio was $3: 1$. Mild, moderate and severe injuries were observed in 52\%, 30\% and 18\%, respectively. Surgical interventions were required for $32 \%$ and the overall mortality in the series was $18 \%$ [34]. In Yemen, during 1998-2000, the prevalence of brain injury was 219 per 100,000 with rates among adults and children being 160 and 480 per 100,000 population respectively. The major causes were domestic accidents and traffic injuries in $55 \%$ and $40 \%$ of cases respectively [68].

\subsection{Africa}

Most literature from Africa discusses head injury, and not the more precise clinical entity of traumatic brain injury; this makes literature from Africa difficult to use for intercontinental comparisons, as recent studies from most industrialized countries address TBI 
more precisely. An added challenge is that most studies are hospital based, with vaguely defined catchment populations. This is compounded by the fact that access to health care services is poor in most of Africa, meaning that while the milder TBI go unreported and untreated, the more severe ones may die before reaching hospitals and thus do not get captured in health statistics. Thus with data from mostly urban based secondary and tertiary hospitals, the loss of information happens at both ends of the severity spectrum. Finally, there are no all-age incidence figures published on TBI in Africa; different rates have been published from studies focusing on either adult or childhood TBI.

A hospital based cross-sectional study in Nigeria that covered all ages for patients treated for trauma in the emergency room found that $31 \%$ of all trauma deaths were due to severe TBI [71]. Nell and others found an adult ( $>15$ years) annual incidence rate of 316 per 100,000 residents of Johannesburg, South Africa [62]. There was a wide variation among racial, sex, and age groups, with African males aged 25-44 having the highest rate at 763 per 100,000 . A study that focused on children (aged less than 13 years) treated at a trauma unit in Cape Town, South Africa found that $9 \%$ of the children had TBI [40]. It should be noted that South African society has a history of officially sanctioned racial discrimination (apartheid) which was violently enforced, leading to extreme disparities in income and access to resources and social services, and high levels of violence; this makes it difficult to extrapolate these results to other African countries.

Studies from Africa show two distinct peaks for TBI, one in children below 10 years and the other in adolescents and young adults [56,61]. Those aged 15-24 and 25-44 years tend to be involved in both violence and RTI. The same patterns are seen in both nonfatal and fatal TBIs. Odebode and Abubakar showed a clear peak for head injuries due to RTI among the 6-10 year olds, and a peak for head injuries due to falls among those ages 2-5 years [63]. TBIs are a predominantly male disease in Africa; Laloo and Van As showed a male: female ratio of $1.4: 1$ in children aged 13 and below. In young adults the ratio is much higher and Muyembe and Suleman found an all age male: female ratio of 5.69:1, but in children 5 years and younger the ratio was 1.7:1 [61]. A study in South Tunisia found that $89 \%$ of the patients admitted to the intensive care unit with head injury were male [5]. In Durban, South Africa, a study of civilian infra-tentorial gunshot injuries seen over a 14 year period found all patients to have been male, with $80 \%$ of them being victims of assaults.
The leading causes of TBI in most of Africa are RTI, violence, and falls. Nell et al. found that interpersonal violence accounted for $41.5 \%$ of all nonfatal TBI, and $36.4 \%$ of fatal TBIs in persons aged 15 years and over. There was a wide variation between the races; for instance while violence caused $51 \%$ of nonfatal and $47 \%$ of fatal TBIs in African males, it only caused $10 \%$ of nonfatal and $19 \%$ of fatal TBIs in white males [62]. Many mechanisms of injury have been reported - striking with blunt objects, stabs, use of firearms, and battering in children $[5,40]$. In the Johannesburg study, RTI accounted for $69.6 \%$ of white male nonfatal and $40.5 \%$ of fatal TBIs, compared to $25.6 \%$ nonfatal and $41.5 \%$ fatal TBIs in African males [62]. Adesunkanmi found that of the 17 pediatric head injuries with a GCS of less than 8, fourteen were from RTI; the most serious TBI tend to occur in pedestrians and those on two wheelers [40]. Falls are an important cause of TBI, particularly in young children $[3,40,50]$; most falls resulting in TBI occur at home.

A study in the Gambia which defined children as being 14 years and below found that $16.2 \%$ of all pediatric trauma admissions had closed head injury, and accounted for $7.1 \%$ of hospital days [67]. Adesunkanmi et al. (2000) studied Nigerian children 14 years and below who had been involved in road traffic crashes $(N=$ 324 ) over a period of four years. Head injuries were the leading specific injury type with $25.3 \%$ of injured children having a Glasgow Coma Score (GCS) of less than 13 [4]. In Laloo's study which looked at childhood TBI, falls were the leading cause of TBI admissions (41\%), followed by road traffic crashes [40].

\subsection{Country example: India}

Rapid industrialization, urbanization, motorization, economic liberalization and changing social environments are the hallmarks of new India in recent years. The number of vehicles on Indian roads has increased from 5.3 to 59 million during 1981-2002 [53]. The complex interactions of human, vehicle and environmental factors along with absence of safety environments and regulations has led to an increase of morbidity, mortality, disabilities and social economic losses from TBI in India. Recent national estimates reveal that $850,000-1,000,000$ persons are killed every year in India due to an injury; and the ratio of deaths:serious injuries:mild injuries has been estimated at 1:15:70 [26]. Injuries are highly underreported in India due to the varied nature of hospital and police reporting systems, mix of public and private health care providers, medico- 
legal nature of injuries, stigma with regard to violence and compensation issues.

Nearly one fourth of all injuries among hospital registered patients in India are TBIs. It is estimated that nearly 2 million persons are injured and 200,000 die due to TBI [25]. Studies of TBI have shown that men in the 15-45 year age group and those from rural areas are involved in greater numbers in TBI. In a recent TBI registry from Bangalore, it has been shown that $77 \%$ were young and middle-aged adults and $5 \%$ were children; the male to female ratio was 4:1 [29]. RTIs account for $45-60 \%$ of TBIs in different parts of the country; pedestrians (30-40\%), motorized two wheeler occupants (40-40\%), and bicyclists (5-10\%) comprise the majority of victims [25]. The second leading cause are falls occurring at home (staircases and top of buildings), playgrounds, agricultural sites (fall from trees) and workplaces accounting for $20-30 \%$ of TBI. Violence from blunt and penetrating objects is responsible for an additional $10 \%$ of TBI and commonly seen among young men.

Among risk factors for TBI, alcohol consumption is a major one due to increasing availability of alcohol, greater purchasing power of people, and the absence of defined regulations; with an estimated 70 million users, India is facing a huge burden of alcohol related problems [28]. The mortality and disability rates among those TBI under the influence of alcohol are nearly 1.5 to two times higher, resulting in higher extent of mortality and consequent disabilities [23]. Recent Bangalore studies have shown that $16-25 \%$ of hospital registered TBIs were under the influence of alcohol which also poses major problems for diagnosis, management and recovery $[13,29]$.

The accessibility and affordability of emergency services is another determining factor affecting the consequences of TBIs. Emergency care in India is more of an urban phenomena and studies $[29,38]$ have demonstrated that absence of first aid, delayed transportation to a definitive hospital, absence of triage, and inappropriate referral contribute to increasing severity and mortality from TBI. While there are reports of a decline in case fatality rates from TBI in urban tertiary care hospitals due to improved [29], access to such services is beyond the reach of most people in the country. In addition, tertiary care in public hospitals is highly variable for TBI and the country has only 800 neurosurgeons - nearly all of them concentrated in urban areas.

Nearly one million persons would require rehabilitation services at any given point of time for TBI consequences in India. In a follow-up of 425 sub- jects at four months post discharge, it was observed that $43 \%$ had different post-traumatic sequelae ranging from headache to a wide spectrum of behavioral problems [27]. A recent TBI registry shows that $18 \%$ of patients had various post-traumatic sequelae, major economic problems, and poor quality of life at two years post discharge [29]. Among 607 patients, 10\% could not continue their previous jobs, $8 \%$ reported themselves to be unfit for any work, nearly $25 \%$ had incurred heavy expenditure, $48 \%$ reported loss of income, and $72 \%$ had to borrow money apart from selling their previous assets [29]. However, despite mounting deaths and disabilities efforts towards prevention of TBI are limited in India. There is an urgent need to implement proven control measures such as safer pedestrian environment, speed control, promote helmet usage, restrict alcohol consumption, strengthen prehospital and acute trauma care, and better rehabilitation programs.

\section{Implications for research and control}

The burden of TBI is manifest in all regions of the world, and is especially prominent in low and middle income countries. Even in high income countries, TBI management including intensive care, differs across countries and best practices remain elusive. Access to tertiary neurosurgical and rehabilitation units is limited in rural environments and in the poorest regions of the world such as Sub-Saharan Africa. It is estimated that although over $80 \%$ of the world's people with disabilities live in LMIC, only $2 \%$ have access to rehabilitation services [36]. This lack of treatment and long term care service calls for comprehensive rehabilitative facilities based on trained manpower to enable and empower people affected by TBI to have a increased quality of life. However, a detailed analysis of such care is outside the scope of this paper.

The loss of life, the potential for life-long morbidity, and the social and financial implications makes TBI a pressing public health and medical problem. Developing countries face a double-hazard with respect to TBI; they have a high preponderance of risk factors for TBI, while at the same time they are the least prepared to address TBI when they happen. Thus, both the incidence of TBI and the case-fatality from TBI can be high and devastating.

The quantity and quality of data from around the world, especially LMIC, is far from ideal. Facilitybased data, small-scale studies, case-series of one diagnosis, and non-standardized approaches create chal- 
lenges for the development of an accurate epidemiological profile for TBI. Data on TBI is not specifically tracked at WHO although efforts are underway to improve this situation [51]. In addition, there is a large gap from most parts of the world in terms of data on long-term sequelae, financial cost, and social impact of TBI. Of particular importance is the need to address the paucity of data with regards to childhood TBI, since up to $75 \%$ of injured children admitted to hospital are reported have sustained a TBI [41], and neurological injuries result in more death and disability than all other pediatric problems combined. Yet despite this, the importance of TBI in children is often neglected.

The efforts towards primary, secondary and tertiary prevention of TBI have been far from satisfactory in LMIC. There have been improvements in road design and promotion of safety interventions such as seat belts, motor cycle helmets, and child seats to reduce the number and severity of TBI [82]. Improvements in the design and construction of buildings, play areas and work places along with improved parental and caregiver supervision can reduce the number of falls among both children and the elderly. Violence prevention measures aimed at the restriction and availability of weapons has provided positive results [80]. Improvements in trauma care with low cost solutions based on minimizing the time interval between injury and care, triage, and efficient hospital management can help to further reduce the serious outcomes of TBI [54]. Tertiary prevention with comprehensive physical, psychological and vocational rehabilitation measures can reduce disabilities due to TBI and consequently improve quality of life.

There are a number of organizations and institutions involved in care, research and prevention of neurotrauma such as the European Brain Injury Society, the International Brain Injury Association, the Neurotrauma Society, the International Association for the Study of Traumatic Brain Injury and Rehabilitation International. Clearly collaboration between such bodies with clear leadership from an international organization such as the WHO, is required. Joint programs between developed and developing countries should also be encouraged at both regional and national levels.

The public health approach to prevention of injuries including TBI, focuses on identifying the burden and risk factors, choosing prioritized interventions and evaluating the effectiveness of these interventions. It is crucial to plan comprehensive TBI prevention, management and rehabilitation programs around the world, especially in developing countries, that are evidencebased. Such programs may involve many different op- erational layers - research, policy formulation, public and political education, publicity campaigns, legislation, changes in manufacturing practice, as well as environmental and system modification [79]. In order to strengthen cooperation, research focusing on primary prevention, emergency care and rehabilitative services, should be promoted in collaboration with developed countries with established research programs. Prioritizing and coordinating funds for the generation of appropriate evidence and research is critical to meet the need to promote evidence-based policy for TBI.

\section{Acknowledgements}

The authors would like to thank: Jacob A. Neufeld for encouraging the writing of this paper; Colin D. Mathers of WHO and Walter Vedatta of the Latin American Brain Injury Consortium for responding to data queries; and many colleagues who responded to our e-mails for information.

\section{References}

[1] http://www.nabis.org/public/bfacts.shtml, accessed: 12th December 2006.

[2] Research and Training Center in Rehabilitation and Childhood Trauma: Injuries among children. IN: The Pediatric Trauma Registry. Boston: Tufts University School of Medicine, New England Medical Center, 1993.

[3] A.R. Adesunkanmi, L.M. Oginni, A.O. Oyelami and O.S. Badru, Epidemiology of childhood injury, J Trauma 44(3) (1998), 506-512.

[4] A.R. Adesunkanmi, L.M. Oginni, O.A. Oyelami and O.S. Badru, Road traffic accidents to african children: assessment of severity using the injury severity score (ISS), Injury 31(4) (2000), 225-228.

[5] M. Bahloul, H. Chelly, M. Ben Hmida, C. Ben Hamida, H. Ksibi, H. Kallel, A. Chaari, M. Kassis, N. Rekik and M. Bouaziz, Prognosis of traumatic head injury in South Tunisia: a multivariate analysis of 437 cases, J Trauma 57(2) (2004), 255-261.

[6] S. Bartlett, The problem of children's injuries in low-income countries: a review, Health Policy Plan 17 (2002), 1-13.

[7] Brain Injury Association of America, www.biausa.org $>$.

[8] Brain Injury Association of New Mexico, 6th December 2006, http://www.braininjurynm.org/>.

[9] R. Briceño-León, Violence and the Right to Kill: Public Perceptions from Latin America, Central University of Venezuela, Venezuela.

[10] J. Bruns, Jr. and W.A. Hauser, The epidemiology of traumatic brain injury: a review, Epilepsia 44(Suppl 10) (2003), 2-10.

[11] Canadian Institute for Health Information, Head Injuries in Canada: A Decade of Change (1994-1995 to 2003-2004), (August 2006. Found on: www.cihi.ca). 
[12] H. Chan, W. Aasim, N. Abdullah, N. Naing, J. Abdullah, M. Saffari and A. Osman, Characteristics and clinical predictors of minor head injury in children presenting to two Malaysian accident and emergency departments, Singapore Med J 46(5) (2005), 219-223.

[13] C.J. Cherpitel, Y. Ye, J. Bond, J. Rehm, M. Cremonte, O. Neves, J. Moskalewicz, G. Swiatkiewicz and N. Giesbrecht, The effect of alcohol consumption on emergency department services use among injured patients: A cross-national emergency room study, J Stud Alcohol 67(6) (2006), 890-897.

[14] A.R. Colohan, W.M. Alves, C.R. Gross, J.C. Torner, V.S. Mehta, P.N. Tandon and J.A. Jane, Head injury mortality in two centers with different emergency medical services and intensive care, J Neurosurg 71(2) (1989), 202-207.

[15] A. Davis, A. Quinbly, W. Odero, G. Gururaj and M. Hijaar, Improving Road Safety by reducing impaired driving in developing countries: A scoping study, TRL review.

[16] A. De Andrade, R. Marino, O. Ciquini, E. Figueiredo and A. Machado, Guidelines for Neurosurgical Trauma in Brazil, World Journal of Surgery V25(9) (2001), 1186-1201.

[17] C.F. Eiben, T.P. Anderson, L. Lockman, D.J. Matthews, R. Dryja, J. Martin, C. Burrill, N. Gottesman, P. O’Brian and L. Witte, Functional outcome of closed head injury in children and young adults, Arch Phys Med Rehabil 65(4) (1984), 168170.

[18] I. Emanuelson and L. Wendt, Epidemiology of traumatic brain injury in children and adolescents in south-western Sweden, Acta Paediatrica 86(7) (1997), 730-735.

[19] R. Firsching and D. Woischneck, Present Status of Neurosurgical Trauma in Germany, World Journal of Surgery V25(9) (2001), 1221-1223.

[20] B. Gabella, R.E. Hoffman, W.W. Marine and L. Stallones, Urban and rural traumatic brain injuries in Colorado, Ann Epidemiol 7(3) (1997), 207-212.

[21] K.Y. Goh and W.S. Poon, Children's head injuries in the Vietnamese refugee population in Hong Kong, Injury 26(8) (1995), 533-536.

[22] G. Gururaj, Alcohol and road traffic injuries in South Asia: challenges for prevention, J Coll Physicians Surg Pak 14(12) (2004), 713-718.

[23] G. Gururaj, The effect of alcohol on incidence, pattern, severity and outcome from Traumatic Brain Injury, Journal of Indian Medical Association 102 (2004), 157-160.

[24] G. Gururaj, An epidemiological approach to prevention - prehospital care and rehabilitation in neurotrauma, Neurology India 43(3) (1995), 95-105.

[25] G. Gururaj, Epidemiology of traumatic brain injuries: Indian scenario, Neurological Research 24 (2002), 24-28.

[26] G. Gururaj, Injuries in India: A National Perspective Burden of disease in India, National Commission on Macroeconomics \& Health. Ministry of Health \& Family Welfare, G. o. India (ed.), India, 2005, 325-347.

[27] G. Gururaj, S. Channabasavanna, B. Das and V. LKaliaperumal, Epidemiology of Head Injuries; Summary Report, N. I. o. M. H. a. Neurosciences (ed.), 1994.

[28] G. Gururaj, N. Girish and M. Issac, Mental, neurological and substance abuse disorders: strategies towards a systems approach. Burden of disease in India, National Commission on Macroeconomics \& Health, M. o. H. F. Welfare (ed.), Government of India, India, 2005, 225-250.

[29] G. Gururaj, S. Kollury, B. Chandramouli, D. Subbakrishna and J. Kraus, Traumatic Brain Injury, NIMHANS Publication 61 (2005), 1-53.
[30] G. Gururaj and V. Sateesh, Assessment of facilities at casualty and emergency care services in Bangalore hospitals, J Acad Hosp Admin 11 (1999), 9-11.

[31] M.C. Hijar-Medina, C.E. Carrillo-Ordaz, M.E. Flores-Aldana, R. Anaya and M.V. Lopez-Lopez, Risk factors for injuries caused by traffic accidents and the impact of an intervention on the road, Rev Saude Publica 33(5) (1999), 505-512.

[32] S.L. Hillier, J.E. Hiller and J. Metzer, Epidemiology of traumatic brain injury in South Australia, Brain Inj 11(9) (1997), 649-659.

[33] C.W. Hukkelhoven, E.W. Steyerberg, E. Farace, J.D. Habbema, L.F. Marshall and A.I. Maas, Regional differences in patient characteristics, case management, and outcomes in traumatic brain injury: experience from the tirilazad trials, $J \mathrm{Neu}$ rosurg 97(3) (2002), 549-557.

[34] R. Iftikhar Ali, V. Anjum Habib and M.B.B.S. Mubasher Ahmed, Neurotrauma in Pakistan, World Journal of Surgery V25(9) (2001), 1230-1237.

[35] A. Indrayan, M. J. Wysocki, R. Kumar, A. Chawla and N. Singh, Estimates of the years-of-life-lost due to the top nine causes of death in rural areas of major states in India in 1995, Natl Med J India 15(1) (2002), 7-13.

[36] D. Jamison, J. Breman, A. Measham, G. Alleyne, M. Claeson, D. Evans, P. Jha, A. Mills and P. Musgrove, Disease Control Priorities in Developing Countries, 2nd edition ed., 2006.

[37] E. Javouhey, A.C. Guerin, M. Chiron and D. Floret, Epidemiology and prevention of head trauma in children, Arch Pediatr 13(6) (2006), 528-530.

[38] M.K. Joshipura, H.S. Shah, P.R. Patel, P.A. Divatia and P.M. Desai, Trauma care systems in India, Injury 34(9) (2003), 686-692.

[39] D.F. Kelly and D.P. Becker, Advances in management of neurosurgical trauma: USA and Canada, World J Surg 25(9) (2001), 1179-1185.

[40] R. Lalloo and A.B. van As, Profile of children with head injuries treated at the trauma unit of Red Cross War Memorial Children's Hospital, 1991-2001, S Afr Med J 94(7) (2004), 544-546.

[41] W. Lam and A. Mackersie, Paediatric head injury: incidence, aetiology and management, Paediatr Anaesth 9 (1999), 377385.

[42] J. Langlois, S. Kegler and J. Butler, Traumatic brain injuryrelated hospital discharges: results from a fourteen state surveillance system, Morbidity and Mortality Weekly Reports 2003, 52:SS-04, 1997, 1-18.

[43] J.A. Langlois, W. Rutland-Brown and K. Thomas, Traumatic brain injury in the United States: emergency department visits, hospitalizations, and deaths, N.C.f.I.P.a. Control (ed.), Centers for Disease Control and Prevention, Atlanta (GA), 2006.

[44] J.A. Langlois, W. Rutland-Brown and K.E. Thomas, The incidence of traumatic brain injury among children in the United States: differences by race, J Head Trauma Rehabil 20(3) (2005), 229-238.

[45] J.A. Langlois, W. Rutland-Brown and M.M. Wald, The epidemiology and impact of traumatic brain injury: a brief overview, J Head Trauma Rehabil 21(5) (2006), 375-378.

[46] M. Lee, W. Chiu, L. Chang, S. Liu and S. Lin, Craniofacial injuries in unhelmeted riders of motorbikes, Injury 26 (1995), 467-470.

[47] E. Lehr, Incidence and Etiology. In: Psychological Management of Traumatic Brain Injuries in Children and Adolescents, Aspen Publishers, Rockville, MD, 1990. 
[48] D. Leipziger, The unfinished poverty agenda: Why Latin America and the Caribbean lag behind, Finance and Development 38(1) (2001).

[49] L. Levi, S. Linn, M. Revach and M. Feinsod, Head trauma in northern Israel: incidence and types, Neuroepidemiology 9(5) (1990), 278-284.

[50] N. Masiira-Mukasa and B.R. Ombito, Surgical admissions to the Rift Valley Provincial General Hospital, Kenya, East Afr Med J 79(7) (2002), 373-378.

[51] C. Mathers, Tracking of TBI Data at WHO, A. Hyder, ed., Baltimore, 2006

[52] J.R. Melo, R.A. Silva and E.D. Moreira, Jr., Characteristics of patients with head injury at Salvador City (Bahia-Brazil), Arq Neuropsiquiatr 62(3A) (2004), 711-714.

[53] Ministry of Shipping Road Transport and Highways, www. morth.nic.in $>$.

[54] Mock, Joshipura, Quansah and R. Arreola, Advancing injury prevention and trauma care in North America and globally, Surgical Clinics of North America 87(1) (2007), 1-19.

[55] K. Mukhida, M. Sharma and S. Shilpakar, Pediatric neurotrauma in Kathmandu, Nepal: implications for injury management and control, Childs Nerv Syst 22 (2006), 352-362.

[56] E. Muniu, M.N. Katsivo, L.W. Mwaura and M. Amuyunzu, Fatal non-transport injuries in Nairobi, Kenya, East Afr Med J 71(6) (1994), 346-349.

[57] A. Murgio, F.A. Andrade, M.A. Sanchez Munoz, S. Boetto and K.M. Leung, International multicenter study of head injury in children. ISHIP Group, Childs Nerv Syst 15(6-7) (1999), 318-321.

[58] A. Murgio, J. Fernandez Mila, A. Manolio, D. Maurel and C. Ubeda, Minor head injury at paediatric age in Argentina, $J$ Neurosurg Sci 43(1) (1999), 15-23; discussion 23-14.

[59] C.J. Murray and A.D. Lopez, The Global Burden of Disease: A Comprehensive Assessment of Mortality and Disability from Diseases, Injuries, and Risk Factors in 1990 and Projected in 2020. Harvard University Press, Boston: Harvard School of Public Health, 1996.

[60] C.J. Murray and A.D. Lopez, Global Health Statistics: A Compendium of Incidence, Prevalence and Mortality Estimates for Over 200 Conditions. Harvard University Press, Cambridge, 1996.

[61] V.M. Muyembe and N. Suleman, Head injuries at a Provincial General Hospital in Kenya, East Afr Med J 76(4) (1999), 200205.

[62] V. Nell and D.S. Brown, Epidemiology of traumatic brain injury in Johannesburg-II. Morbidity, mortality and etiology, Soc Sci Med 33(3) (1991), 289-296.

[63] T.O. Odebode and A.M. Abubakar, Childhood head injury: causes, outcome, and outcome predictors. A Nigerian perspective, Pediatr Surg Int 20(5) (2004), 348-352.

[64] R.C. Parslow, K.P. Morris, R.C. Tasker, R.J. Forsyth and C.A. Hawley, Epidemiology of traumatic brain injury in children receiving intensive care in the UK, Arch Dis Child 90(11) (2005), 1182-1187.

[65] Population Division of the Department of Economic and Social Affairs of the United Nations Secretariat, World Population Prospects: The 2004 Revision and World Urbanization Prospects: The 2003 Revision, 2003.

[66] P. Sahdev, M.J. Lacqua, B. Singh and T.D. Dogra, Road traffic fatalities in Delhi: causes, injury patterns, and incidence of preventable deaths, Accid Anal Prev 26(3) (1994), 377-384.

[67] C. Shen, B. Sanno-Duanda and S.W. Bickler, Pediatric trauma at a government referral hospital in The Gambia, West Afr J Med 22(4) (2003), 287-290.

[68] A.A. Shukri, V.P. Bersnev and N.P. Riabukha, The epidemiology of brain injury and the organization of health care to victims in Aden (Yemen), Zh Vopr Neirokhir Im N N Burdenko 2 (2006), 40-42; discussion 42.

[69] D.S. Sidhu, G.S. Sodi and A.K. Banerjee, Mortality profile in trauma victims, J Indian Med Assoc 91(1) (1993), 16-18.

[70] M.S. Singer and A. Ghaffar, Risk factors for road traffic injury in Pakistani children, J Coll Physicians Surg Pak 14(12) (2004), 709-712.

[71] B.A. Solagberu, Spinal cord injuries in Ilorin, Nigeria, West Afr J Med 21(3) (2002), 230-232.

[72] S. Srinath, S.C. Girimaji, G. Gururaj, S. Seshadri, D.K. Subbakrishna, P. Bhola and N. Kumar, Epidemiological study of child and adolescent psychiatric disorders in urban and rural areas of Bangalore, India, Indian J Med Res 122(1) (2005), 67-79.

[73] M. Sznajder, B. Chevallier, G. Leroux, C. Bruneau, J. Yacoubovitch and B. Auvert, Frequency of childhood injuries: first results of the Boulogne-Billancourt registry, Rev Epidemiol Sante Publique 49(2) (2001), 125-134.

[74] A. Tabish, N.A. Lone, W.M. Afzal and A. Salam, The incidence and severity of injury in children hospitalised for traumatic brain injury in Kashmir, Injury 37(5) (2006), 410-415.

[75] F. Tagliaferri, C. Compagnone, M. Korsic, F. Servadei and J. Kraus, A systematic review of brain injury epidemiology in Europe, Acta Neurochir (Wien) 148(3) (2006), 255-268; discussion 268

[76] R.L. Tate, S. McDonald and J.M. Lulham, Incidence of hospital-treated traumatic brain injury in an Australian community, Aust N Z J Public Health 22(4) (1998), 419-423.

[77] D.J. Thurman, C. Alverson, K.A. Dunn, J. Guerrero and J.E. Sniezek, Traumatic brain injury in the United States: A public health perspective, J Head Trauma Rehabil 14(6) (1999), 602615.

[78] UNICEF Innocenti Research Centre, A League Table of Child Deaths by Injury in Rich Nations: Innocenti Report Card. No. 2 ed., UNICEF, Florence, February 2001.

[79] World Health Organization, The ICD-10 Classification of Mental and Behavioural Disorders, 12/01/06, http://www. who.int/classifications/icd/en/GRNBOOK.pdf $>$.

[80] World Health Organization, Projections of Mortality and Burden of Disease to 2030: Deaths by Income Group, Projections of Mortality and Burden of Disease to 2030, Geneva, 2002.

[81] World Health Organization, World Health Report 2003. Shaping the Future., World Health Organization, Geneva, 2003.

[82] World Health Organization, World Health Report - Changing History, 2004.

[83] P.J. Yates, W.H. Williams, A. Harris, A. Round and R. Jenkins, An epidemiological study of head injuries in a UK population attending an emergency department, J Neurol Neurosurg Psychiatry 77(5) (2006), 699-701.

[84] Y.-D. Zhao and W. Wang, Neurosurgical trauma in People's Republic of China, World Journal of Surgery V25(9) (2001), 1202-1204. 